\title{
The Quality of Life of African American Women with Breast Cancer
}

\author{
Laurel L. Northouse, ${ }^{1 *}$ Michelle Caffey, ${ }^{2 \dagger}$ Lee Deichelbohrer,${ }^{3 *}$ Lisa Schmidt, $4 \$$ \\ Lynette Guziatek-Trojniak, ${ }^{5 \text { II }}$ Sharon West, ${ }^{6 \#}$ Trace Kershaw, ${ }^{7 * * *}$ Darlene Mood ${ }^{8 *}$
}

\author{
${ }^{1}$ School of Nursing, University of Michigan, 400 N. Ingalls, Ann Arbor, MI, 48109 \\ ${ }^{2}$ North Oakland Medical Center, Pontiac, MI \\ ${ }^{3}$ Collaborative Practice, Trenton, MI \\ ${ }^{4}$ Counseling/Support Services, Walled Lake, MI \\ ${ }^{5}$ Karmanos Cancer Institute, Detroit, MI \\ ${ }^{6}$ MacClaren Hospital, Flint, MI \\ ${ }^{7}$ Center for Health Research, Wayne State University \\ ${ }^{8}$ College of Nursing, Wayne State University \\ Received 26 June 1998; accepted 16 June 1999
}

\begin{abstract}
The objectives of this study were to describe the quality of life of African American women with breast cancer and test a model of factors that may affect their quality of life. A stresscoping framework that included person (demographics, current concerns, and optimism), social resources (family functioning), and illness-related factors (symptom distress, medical characteristics), as well as appraisal of illness and quality of life, was used to guide this exploratory, crosssectional study. Participants included 98 African American women who were approximately 4 years postdiagnosis. The women reported a fairly high quality of life, were generally optimistic, and had effective family functioning. Although symptom distress was generally low, a sizable number of women reported problems with energy loss, sleep disturbances, and pain. The model explained $75 \%$ of the variance in quality of life, with appraisal, family functioning, symptom distress, and recurrence status each explaining a significant amount of the variance. Current concerns had an indirect effect on quality of life that was mediated by appraisal. These findings underscore the importance of helping women foster a positive appraisal of their illness, manage current concerns, maintain family functioning, and reduce symptom distress, because each of these factors indirectly or directly affects their quality of life. (c) 1999 John Wiley \& Sons, Inc. Res Nurs Health 22:449-460, 1999
\end{abstract}

Keywords: breast cancer; quality of life; African American; stress and coping

The quality of life of African American women with breast cancer is a significant health care issue. African American women are more likely to be diagnosed with an advanced stage of breast cancer than are Caucasian women, and their sur- vival rates are significantly lower at all stages of disease (Boring, Squires, \& Heath, 1992). African American women from lower socioeconomic levels fare the worst of all in terms of survival; their survival rates are significantly lower than African

The authors acknowledge the contributions and critique provided by Dr. Marilyn Oberst of Wayne State University.

Contract grant sponsors: Dean's Discretionary Fund; Small Project Grant from Wayne State

University.

Correspondence to Laurel L. Northouse.

*Professor.

${ }^{\dagger}$ Nurse Educator.

¥Nurse Practitioner.

§Psychiatric Nurse Practitioner.

"Clinical Nurse Specialist.

\#Clinical Nurse Manager.

${ }^{* *}$ Statistical Assistant. 
American women from higher socioeconomic groups and lower than Caucasian women in general (Freeman \& Wasfie, 1989).

Although African American women with breast cancer have lower survival rates, few researchers have examined their quality of life following the diagnosis of breast cancer. For the most part, prior research has focused on the breast cancer screening and detection practices of African American women (Burack et al., 1989; Lauver, 1992; Phillips, Cohen, \& Moses, 1999; Price, Desmond, Slenker, Smith, \& Stewart, 1992) or on their survival rates once their breast cancer has been diagnosed (Boring et al., 1992; Dayal, Power, \& Chiu, 1982; Freeman \& Wasfie, 1989; Reynolds et al., 1994). There is a notable absence of studies that have examined how African American women manage their breast cancer or its impact on their lives following diagnosis (Powell, 1994). In order for health professionals to intervene effectively with all breast cancer patients, more research is needed on the experiences of women from a variety of racial and cultural backgrounds. The purpose of this study was to examine the quality of life of African American women with breast cancer and to identify factors that affect their quality of life.

A cognitive appraisal model of stress and coping (Lazarus \& Folkman, 1984; Scott, Oberst, \& Dropkin, 1980) was used to guide this study (see Figure 1). Based on the model, it was hypothesized that antecedent factors such as women's personal characteristics (demographics, optimism, and current concerns), their social resources (family functioning), and illness-related factors (symptom distress, ex- tent of disease, etc.) would influence how women appraised their illness. Furthermore, it was hypothesized that appraisal would have a direct effect on quality of life and mediate the relationship between the antecedent factors and quality of life.

The person factors that were of primary interest in this study were demographics, optimism, and current concerns. Of the demographic variables, age has received the most attention in the breast cancer literature, with reports that younger women have more emotional distress than older women during the first year following diagnosis (Penman et al., 1986; Vinokur, Threatt, Vinokur-Kaplan, \& Satariano, 1990) and during the survivor phase of illness (Ganz, Rowland, Desmond, Meyerowitz, \& Wyatt, 1998; Vinokur, Threatt, Caplan, \& Zimmerman, 1989). Education also has been related to adjustment, with women having less education reporting more adjustment difficulties than women having more education (Northouse, Dorris, \& Charron-Moore, 1995). Low income has been related to an increase in perceived health threat among breast cancer survivors (Vinokur et al., 1989) and to poorer survival rates among African American women with breast cancer (Freeman \& Wasfie, 1989) and, thus, may be related to lower quality of life.

Optimism has been associated with better adjustment to breast cancer (Carver et al., 1993; Carver et al., 1994); however, this relationship has been assessed primarily in samples of Caucasian women. Optimism is especially relevant because African Americans are reported to have a more fatalistic outlook about cancer (Powe, 1995; Powe $\&$ Weinrich, 1999) and a more pessimistic view of

Antecedents

Mediator

Outcome

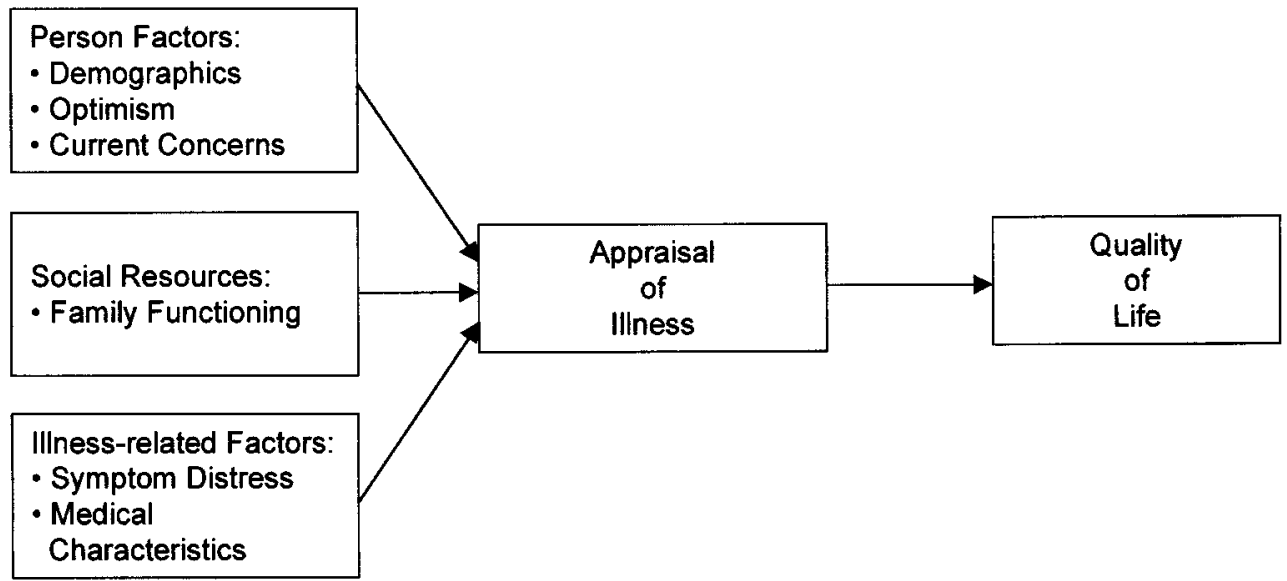

FIGURE 1. Theoretical framework. 
their health in general than do Caucasians (Ferraro, 1993). It is not clear how much optimism African American women have after they are diagnosed with breast cancer because so few studies have been conducted with this group of women. Current concerns, or the number of other concerns experienced by women at the same time they are dealing with breast cancer, have been related to adjustment in a number of studies (Hough, Lewis, \& Woods, 1991; Maunsell, Brisson, \& DeSchenes, 1992; Penman et al., 1986). Even among longterm cancer survivors, a higher number of concerns was associated with poorer adjustment to the illness at 6 year follow-up (Grassi \& Rosti, 1996). There have been few investigators, however, who have examined the concurrent concerns experienced by African American women with breast cancer or the influence that these concerns have on women's quality of life.

Social resources also have been related to quality of life outcomes. In this study, family functioning (the degree to which family members were able to help and support one another) was the social resource of primary interest. Higher levels of family functioning have been associated with better adjustment to breast cancer (Lewis, Hammond, \& Woods, 1993). Among African American women, higher levels of social support have been associated with a greater likelihood of having a screening mammogram (Kang \& Bloom, 1993), and longer survival from breast cancer (Reynolds et al., 1994). It was anticipated that family functioning would be related to how women appraise their illness and to their quality of life, given the key role that the family plays in the lives of African Americans (Taylor \& Chatters, 1986).

There are a number of illness-related factors that can affect quality of life (see Figure 1). The amount of symptom distress experienced by an individual has been related to quality of life in a number of studies of people with cancer, especially breast cancer (Longman, Braden, \& Mishel, 1996; Woods \& Earp, 1978). Symptoms such as fatigue, pain, and menstrual problems have been reported as ongoing problems for women with breast cancer (Ferrell et al., 1996), continuing for as long as $2-3$ years following diagnosis (Ganz et al., 1996). In one study, symptom distress was reported as especially problematic for a sample of African Americans of whom $30 \%$ had breast or gynecological cancer (O'Hare, Malone, Lusk, \& McCorkle, 1993). Extent of disease, or the extent to which the cancer has spread to adjacent lymph nodes or to other parts of the woman's body, has been related to poorer adjustment to breast cancer, although the findings have not been consis- tent across studies (Northouse \& Swain, 1987). Whether or not women are receiving active treatment or have experienced a recurrence of their cancer can affect quality of life (Dorval, Maunsell, Deschenes, Brisson, \& Masse, 1998; Northouse, Dorris, \& Charron-Moore, 1995) and needs to be considered in a multivariate model of factors related to women's quality of life following a breast cancer diagnosis.

Appraisal of illness, which is the individual's subjective evaluation of the meaning of the illness, was viewed as a mediator in the model illustrated in Figure 1. Investigators have found that stressful appraisals, which involve beliefs that an illness is associated with potential harm, loss, or threat, partially mediate the direct effect of symptom distress (Munkres, Oberst, \& Hughes, 1992; Oberst, Hughes, Chang, \& McCubbin, 1991) and family hardiness (Carey, Oberst, McCubbin, \& Hughes, 1991) on mood. In this particular study we were interested in how African American women with breast cancer appraised their illness and whether their appraisals mediated the relationships between the antecedent variables and quality of life.

Quality of life, the outcome variable in this study, was viewed as a multidimensional concept that encompassed the individual's sense of wellbeing related to disease or treatment-related symptoms, physical functioning, psychological functioning, and social and role functioning (Aaronson, 1993). There has been considerable research on the quality of life of women who have survived breast cancer (Andrydowski et al., 1996; Dorval et al., 1998; Ferrans, 1994; Ferrell, Grant, Funk, Otis-Green, \& Garcia, 1998; Ferrell, Hassey Dow, \& Grant, 1995; Ganz et al., 1996; Wyatt \& Friedman, 1996), but there has been little research on the quality of life of African American women with breast cancer.

The specific objectives for this study were to (a) describe the quality of life of African American women with breast cancer and (b) test a multivariate model of factors that may affect their quality of life based on a stress-coping model.

\section{METHOD}

A descriptive, correlational, cross-sectional design was used to study the hypothesized relationships.

\section{Sample}

The sample consisted of 98 African American women with breast cancer. Sample size was based 
on power analysis. Past research has shown that social and illness-related antecedents account for $42-56 \%$ of the variance in psychosocial adjustment/quality of life (Northouse, Dorris, \& Charron-Moore, 1995; Northouse, Jeffs, CracchioloCaraway, Lampman, \& Dorris, 1995). A sample size of 98 has a power of .99 to detect a set of 7 variables that account for a total of $45 \%$ of the variance in a multiple regression equation (Cohen, 1988). Furthermore, 98 subjects has the power of .80 to detect a small/medium effect size ( $4 \%$ of the unique variance) for any of the seven predictors above and beyond all of the other predictors.

Criteria for sample selection included African American women with a confirmed diagnosis of breast cancer who were at least one month postdiagnosis. One hundred and forty women initially were approached for the study and $70 \%$ agreed to participate. Women who refused to participate cited reasons such as "too busy" or not "interested." The average age of the participants was 55 years $(S D=12.8$, range 29-81) and the average education level was 13 years $(S D=2.6$, range $7-20)$. Approximately half of the women (54.2\%) were working outside of the home, about one third $(38.6 \%)$ were retired, and the rest $(7.2 \%)$ were unemployed. Of those women who were working, the majority were skilled workers $(40.2 \%)$ or semiprofessionals (28.7\%). Close to a third of the women $(29.7 \%$ ) earned less than $\$ 15,000$ a year, another third $(30.8 \%)$ earned between \$1530,000 , and the remainder $(39.6 \%)$ earned between $\$ 30-75,000+$ per year. Approximately $41 \%$ of the women were married or living with a male companion, $24.5 \%$ were divorced, $21.4 \%$ were widowed, and $13.3 \%$ never married. Most of the women had children $(85 \%)$, with two children being the average $(S D=1.7$, range $1-7)$.

In regard to medical characteristics, the majority of women $(67 \%)$ had no family history of breast cancer. About half of the women $(56 \%)$ found their own breast lump, 25 (26\%) women reported it was detected by mammogram, 15 $(15.5 \%)$ said it was detected by their physician, and $3(3.1 \%)$ said it was found by their husband or companion. For the most part, women did not delay in seeking medical attention after discovering that they had a lump. Sixty-one percent of the women saw a physician within 1 week of finding their lump, 26\% saw their physician within 1 month, and $13 \%$ waited longer than a month. The small group of women who delayed for more than a month said either that they thought that the breast lump would go away, that it was not a problem, or that they feared going to the physician. The mean length of time since diagnosis was 4.6 years
$(S D=3.3$, range $1-15)$, with $75 \%$ of the women being diagnosed within the previous 5 years.

Most of the women had a modified radical mastectomy $(70 \%)$, no cancer in their lymph nodes $(57.4 \%)$, and no cancer in any other part of their body $(88.8 \%)$. Sixteen women $(16.5 \%)$ reported a recurrence of their cancer since initial diagnosis. At the time of the interview, 34 women $(34.7 \%)$ were receiving some type of treatment. Only 17 women (17.3\%) reported trying any type of alternative treatment since diagnosis. The majority of women (89\%) reported getting follow-up mammograms on a regular basis (every 1-2 years) and the majority were doing self-breast exams either often $(54.1 \%)$ or sometimes $(24.5 \%)$.

\section{Concepts, Variables, and Instruments}

Person factors. Demographic variables and concurrent concerns were measured with the Omega Screening Questionnaire (OSQ), originally developed as an interview format by Weisman and Worden (Weisman \& Worden, 1977; Worden, 1983), and adapted to a questionnaire format by Mood and Bickes (1989). The OSQ is comprised of four parts: (a) demographic and background information, (b) health history, (c) inventory of current concerns, and (d) symptoms scale. Two parts of the OSQ, the demographic information section and the inventory of current concerns section, were used to measure person factors. The demographic section of the OSQ includes a number of questions about the respondent's age, education, income, and so forth. The Inventory of Current Concerns is a 40-item scale that asks participants to rate the extent to which they have experienced a list of concerns about issues such as finances (e.g., "I am concerned about needing financial assistance"), children ("I would feel better if my children were more settled in life"), and work ("I would feel better if I could keep up with my work and chores"), in the past month. Participants rate each item according to whether the statement is not true (0), somewhat true (1), or true (2) for them. Individual items are totaled, with higher scores indicating a greater number of current concerns. Validation of the original Omega Screening Questionnaire, including the Inventory of Current Concerns, has been reported previously (Worden, 1983). In the present study, the internal consistency reliability coefficient was .93 .

Optimism was measured with the Life Orientation Test, developed by Scheier and Carver (1985). This scale is comprised of 8 items, plus 4 filler items that are not calculated in the total score. 
Each item (e.g., "I always look on the bright side of things"), is rated on scale from 0 (strongly disagree) to 4 (strongly agree). Individual items are summed (excluding the filler items) with higher scores indicating more dispositional optimism. Evidence of construct validity and internal consistency (alpha $=.76$ ) have been reported previously (Scheier \& Carver, 1985). The internal consistency reliability coefficient for this sample of African American women was .68.

Social factors. Family functioning was measured with the Family APGAR, a 5-item scale developed by Smilkstein (1978) to assess participants' satisfaction with their family's ability to communicate, assist one another, and respond to change. Each item (e.g., "I am satisfied when I can turn to my family for help when something is troubling me") is rated on a scale from 1 (never) to 5 (always). Individual items are summed with higher scores indicating higher family functioning. Reliability and validity information have been reported previously (Smilkstein, Ashworth, \& Montano, 1982). The internal reliability coefficient in this study was .88 .

Illness-related factors. Symptom distress was measured with the Symptoms Scale of the Omega Screening Questionnaire (Mood \& Bickes, 1989). Subjects were asked to rate the extent to which they were experiencing 13 symptoms (e.g., fatigue, breathing problems, pain). Response options are 0 (no trouble), 1 (some), and 2 (a lot). Individual items are summed with higher scores indicating more symptom distress. In previous studies, internal consistency (.75), test-retest reliability (.77), and concurrent validity of the scale have been affirmed (Mood \& Bickes, 1989; Mood, Northouse, \& Oberst, 1995). In the present study, the reliability coefficient for the total scale was .81. Medical characteristics were assessed with a researcher-designed questionnaire on participants' health history and medical treatment history (e.g., type of surgery, lymph node status, time since diagnosis, currently on treatment, recurrence status, and other health problems).

Appraisal. Appraisal of illness was measured with the Appraisal of Illness Questionnaire developed by Oberst (Munkres et al., 1992; Oberst, 1991). The scale consists of 27 scored items (e.g., "this situation threatens to overwhelm me") and 5 unscored filler items, with a 5-point Likert-type response format with choices ranging from 1 (very false) to 5 (very true). Individual items are summed with higher scores indicating more stressful appraisals. Factor analysis of the scale yielded four factors accounting for $65 \%$ of the total variance: threat, loss, financial strain, and general stressfulness (Oberst, 1991). Only the total score was used in this study and the internal reliability coefficient for it was .95.

Quality of life. Quality of life was measured with the breast cancer-specific version of the Functional Assessment of Cancer Therapy Scale (FACT-B, version 3) developed by Cella et al. (1993). The scale consists of 28 general quality of life items (e.g., "I am content with the quality of my life now") and 9 breast cancer specific items (e.g., "I feel sexually attractive"). Each item is rated from 0 (not at all) to 4 (very much). The general items consist of five factors: physical well-being, family well-being, relationship with doctor, emotional well-being, and functional well-being. Subscale scores are tallied and then summed to obtain a total score. Higher scores indicate a higher quality of life. Construct validity, internal consistency, and test-retest reliability of the scale have been reported (Brady et al., 1997). In this study, internal consistency reliabilities for the subscales of the instrument were .80 for physical well-being, .61 for family-social well-being, .51 for relationship with doctor, .79 for emotional well-being, .88 for functional well-being, .66 for additional breast cancer specific items. The reliability coefficient for the total scale was .90 . Only the total scale scores were used in this study.

Readability of the instruments. The reading level of the instruments was assessed using the Flesch-Kincaid Readability Formula (Flesch, 1974). The reading level of the instruments ranged from a fourth grade reading level for the Appraisal of Illness Scale and the Inventory of Current Concerns to an eighth grade reading level for the Family Apgar and the Symptoms Scale of the Omega Screening Questionnaire.

\section{Procedures}

The names of potential participants were obtained from medical oncology offices in the Southeastern region of Michigan. A nurse in each office identified women who met the study criteria and asked them if they would be willing to have a nurse researcher contact them about the study. Women willing to learn more about the study were called by a member of the research staff who explained the study in greater detail. Those women who agreed to participate were scheduled for a data collection session that took place in the woman's home. Prior to the start of data collection, participants signed a consent form which had been approved by the university Institutional Review Board. Although all of the questionnaires were self-report instruments, the data collection nurse 
remained with participants throughout the entire data collection session to answer questions if needed.

\section{Data Analysis}

The overall goal of the data analysis was to assess whether appraisal of illness mediated the effects of person, social, and illness-related antecedents (optimism, current concerns, family functioning, and symptom distress) on quality of life. Mediation was tested using a multistage regression approach outlined by Baron and Kenny (1986). Our main objective was to test a full mediation model as illustrated in Figure 1. However, because few investigators have examined these relationships, and because one study reported partial mediation (Munkres et al., 1992), we also explored the possibility of a partially mediated model. According to Baron and Kenny (1986), a model is fully mediated if the relationship between the antecedent variables and the outcome variable goes from significant to nonsignificant when the mediator is entered into the equation. A model is partially mediated when the significant relationship between the antecedent variables and outcome variable is reduced. In a partially mediated model antecedents could have direct as well as indirect effects on the outcomes.

Based on the review of the literature, optimism, current concerns, family functioning, and symptom distress were considered the primary antecedent variables. Demographic and medical variables were included in the analysis only if they had significant zero-order correlations with either quality of life or appraisal of illness. Of these variables (which included age, education, marital sta- tus, income, type of surgery, lymph node status, time since diagnosis, currently on treatment, recurrence status, and other health problems), only two variables, lymph node status and recurrence status, were significantly related to the mediating or outcome variables. Therefore, they were added to the regression analyses. This resulted in a total of eight variables in the equation: four main antecedent variables (optimism, current concerns, family functioning, and symptom distress), two additional antecedent variables (lymph node status and recurrence status), one mediator variable (appraisal of illness), and one outcome variable, quality of life.

\section{RESULTS}

\section{Description of Quality of Life and Other Study Variables}

Means and standard deviations for all variables, with comparison data from other studies, are shown in Table 1. On the average, the African American women in this study reported a fairly high quality of life. Their overall mean scores on the FACT-B $(116.5, S D=20.7)$ and its subscales were similar or slightly higher than the mean $(112.8, S D=20.9)$ reported for a sample of 295 breast cancer patients, half of whom were African American women (Brady et al., 1997).

Women's mean scores on the Life Orientation Test tended to be optimistic and similar to the mean score obtained for a sample of female college students (Scheier \& Carver, 1985). They also were similar to the mean (25.6) for a primarily Caucasian sample of breast cancer patients (Carver et al.,

Table 1. Descriptive Data on Quality of Life and Other Study Variables

\begin{tabular}{|c|c|c|c|c|}
\hline Variable & Mean & $S D$ & Range & $\begin{array}{l}\text { Comparative Means } \\
\text { From Other Studies }\end{array}$ \\
\hline Quality of life (FACT-B) & 116.5 & 20.7 & $44-145$ & $112.8^{a}$ \\
\hline •Physical & 23.4 & 4.9 & $6-28$ & 22.1 \\
\hline - Social & 22.2 & 4.8 & $4-28$ & 22.7 \\
\hline - Emotional & 17.2 & 3.5 & $4-20$ & 16.3 \\
\hline - Functional & 21.3 & 6.6 & $0-28$ & 20.6 \\
\hline - Relationship with MD & 7.3 & 1.2 & $3-8$ & 7.0 \\
\hline • Additional items & 25.1 & 6.5 & $6-36$ & 24.1 \\
\hline Optimism (LOT) & 23.6 & 4.5 & $13-32$ & $21.4^{b}$ \\
\hline Current concerns (OMEGA) & 23.2 & 16.2 & $0-68$ & - \\
\hline Family functioning (Family APGAR) & 21.9 & 3.9 & $7-25$ & $20.1^{c}$ \\
\hline Symptom distress (OMEGA) & 5.3 & 4.2 & $0-19$ & - \\
\hline Appraisal of illness (AIS) & 2.3 & 0.9 & $1-4$ & $2.9^{d}$ \\
\hline
\end{tabular}

aSample of 295 breast cancer patients (Brady et al., 1997). ' bSample of 267 undergraduate women (Scheier \& Carver, 1985). ' Sample of 58 breast cancer patients (Northouse et al., 1998). dSample of 60 cancer patients with various types of cancer (Munkres et al., 1992). 
1994), although the LOT for that sample was scored on a 4-point scale (no neutral response) versus the 5-point scale used in this study. The average number of current concerns was slightly less than the midpoint on the continuum, indicating a low to moderate number of concerns, but there was wide variability in the scores, with some women reporting few concerns and other women reporting many concerns. Some of the concerns that received the highest ratings were wanting their children more settled in life, wanting to feel closer to God, and worrying about the future. Family functioning scores were relatively high and slightly higher than the mean obtained in a primarily Caucasian sample of breast cancer patients 1 year after surgery (Northouse, Templin, Mood, \& Oberst, 1998).

Symptom distress scores were low to moderate on the average; however, there were certain symptoms that were experienced some or a lot by a sizable number of women. The most frequently reported symptoms were energy loss (56.1\%), sensory problems $(55.7 \%)$, sleep problems (49.5\%), pain (44.9\%), and mental distress (42.3\%). Women's appraisal of illness scores were low to moderate (indicating less stressful appraisals) and slightly below the mean obtained with a heterogeneous sample of cancer patients (see Table 1).

\section{Relationships among Demographic Variables, Medical Variables, and Quality of Life}

None of the demographic variables (i.e., age, education, marital status, income) were significantly related to quality of life. Two medical variables, presence of cancer in the lymph nodes, $t(96)=$ 2.32, $p<.03$, and recurrence of the cancer, $t$ (96) $=2.00, p<.05$, made a significant difference in women's quality of life. Women with cancer in their lymph nodes reported a lower quality of life
$(M=110.8, S D=23.3)$ than women without cancer in their lymph nodes $(M=120.7, S D=17.6)$. Likewise, women whose cancer recurred reported a lower quality of life $(M=107.1, S D=24.5)$ than women whose cancer did not recur $(M=118.2$, $S D=19.5$ ). Other medical variables such as type of surgery, time since diagnosis, currently on treatment, and other health problems were not related to quality of life.

\section{Factors Affecting Quality of Life}

Correlation coefficients among the major study variables are shown in Table 2. A series of regression equations was used to test for mediation (Baron \& Kenny, 1986) and to determine how much variance in quality of life was accounted for by the variables depicted in Figure 1. The first step in the process involved regressing the presumed mediator (appraisal of illness) on the independent variables to determine if they were related. In this analysis, the independent variables accounted for $54 \%$ of the variance in appraisal, with current concerns and symptom distress each making a significant independent contribution to the regression equation. Because these two variables were the only ones that had a significant independent relationship to appraisal, they were the only variables that could be mediated by appraisal.

The second step in the test for mediation involved regressing the outcome variable, quality of life, on the independent variables to determine if they were related. In this analysis, the independent variables accounted for $71 \%$ of the variance in quality of life. Current concerns, family functioning, and symptom distress each made a significant independent contribution to women's quality of life.

The final step in the test for mediation involved regressing quality of life on both the independent variables and the presumed mediator, appraisal of

Table 2. Correlation Among Study Variables $(N=98)$

\begin{tabular}{|c|c|c|c|c|c|c|c|c|}
\hline & $\begin{array}{l}0 \\
1\end{array}$ & $\begin{array}{c}C C \\
2\end{array}$ & $\begin{array}{c}\mathrm{FF} \\
3\end{array}$ & $\begin{array}{c}\text { SD } \\
4\end{array}$ & $\begin{array}{c}\mathrm{Al} \\
5\end{array}$ & $\begin{array}{c}\text { QL } \\
6\end{array}$ & $\begin{array}{c}\text { RS } \\
7\end{array}$ & $\begin{array}{c}\text { LNS } \\
8\end{array}$ \\
\hline 1. Optimism & - & & & & & & & \\
\hline 2. Current concerns & $-.55^{\star *}$ & - & & & & & & \\
\hline 3. Family functioning & $.37^{\star \star}$ & $-.24^{\star}$ & - & & & & & \\
\hline 4. Symptom distress & $-.48^{* *}$ & $.57^{\star *}$ & -.19 & - & & & & \\
\hline 5. Appraisal of illness & $-.52^{* *}$ & $.70^{\star *}$ & $-.20^{\star}$ & $.55^{\star *}$ & - & & & \\
\hline 6. Quality of life & $.57^{\star *}$ & $-.65^{\star *}$ & $.40^{* *}$ & $-.74^{\star *}$ & $-.70^{* *}$ & - & & \\
\hline 7. Recurrence status & .04 & -.01 & -.13 & -.20 & -.05 & $.21^{*}$ & - & \\
\hline 8. Lymph node status & .11 & -.15 & -.03 & -.19 & -.13 & $.24^{*}$ & $.29^{\star \star}$ & - \\
\hline
\end{tabular}

${ }^{*} p<.05 .{ }^{* *} p<.01$. 
illness. The independent variables and appraisal accounted for $75 \%$ of the variance in quality of life. In this analysis, current concerns no longer made a significant independent contribution to quality of life, indicating that appraisal mediates the effect of current concerns on quality of life. Appraisal of illness also appears to serve as a partial mediator between symptom distress and quality of life because, with appraisal in the regression analysis, symptom distress has a slightly smaller beta weight (.41) than when appraisal was not included in the model (.47). However, symptom distress continues to exert a strong direct effect on quality of life, even with the mediating factor, appraisal, in the model. Family functioning and recurrence status were not mediated by appraisal; follow-up analyses indicated that they exerted a direct rather than indirect effect on quality of life. Figure 2 summarizes the relationships between the antecedent variables, appraisal, and quality of life.

\section{DISCUSSION}

One of the important findings in this study was that African American women reported a fairly high quality of life following the diagnosis of breast cancer. Contrary to reports of cancer fatal- ism among African Americans, this sample of women was generally optimistic and for the most part appraised their illness as slightly less stressful than has been reported by a heterogeneous sample of cancer patients (Munkres et al., 1992). The high quality of life reported by many of these women may be attributed to the fact that they were "cancer survivors" who were, on the average, 4 years postdiagnosis. They were also a generally healthy group of women with only a few of them having had a recurrence of their cancer in the interval since diagnosis. The generally high quality of life of this sample of African American women is similar to the findings reported by Ganz and associates (1998) in their study of breast cancer survivors who were approximately 3 years postdiagnosis. They also found a relatively high quality of life among breast cancer survivors that was at or above the level reported by a healthy sample of age-matched controls.

In this study we also tested a model that examined how person, resource, and illness-related factors affected the quality of life of African American women with breast cancer. We found support for some aspects of the model depicted in Figure 1 , and not for others. Appraisal was a key variable in this model and as hypothesized, it had a significant, direct effect on quality of life. Those women
Antecedents

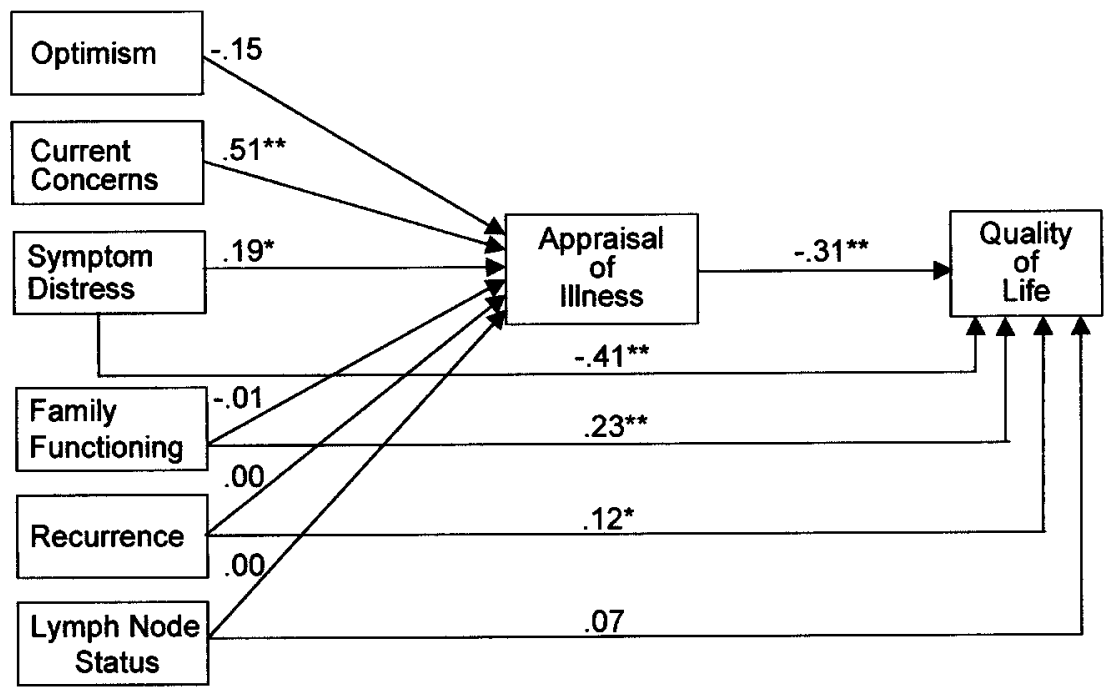

${ }^{*} p \leq .05 .{ }^{* *} p \leq .01$,

FIGURE 2. Summary of factor relationships with quality of life. 
who appraised their illness as more stressful reported significantly lower quality of life than women with less stressful appraisals.

We also hypothesized that appraisal would serve as a mediator in the model, mediating the relationship between the antecedent variables and the outcome variable, quality of life. This hypothesis was partially supported. Appraisal did mediate the relationship between current concerns and quality of life, and partially mediated the relationship between symptom distress and quality of life. It did not mediate the relationship between the other antecedent variables and quality of life. In regards to current concerns, women who reported a higher number of other concerns in their lives reported a more stressful appraisal of their illness and, in turn, a lower quality of life. The African American women in this study reported concerns about their children, their spiritual lives, and their futures. A number of the women were single parents who had either young children, adult children, or both living in their homes. Lewis and colleagues found that single women with breast cancer who had children reported a higher number of illness-related pressures on their families (Lewis, Zahlis, Shands, Sinsheimer, \& Hammond, 1996). It appears that as these other concerns in women's lives increased, they were more likely to view their illness as stressful, which then indirectly affected their quality of life.

Appraisal of illness partially, rather than fully, mediated the relationship between symptom distress and quality of life. Higher symptom distress was related to a more stressful appraisal of illness, and indirectly to a lower quality of life. However, symptom distress also exerted a strong direct effect on quality of life that was not mediated by appraisal. Similar findings were reported by Munkres et al. (1992), who found that appraisal partially mediated the relationship between symptom distress and mood. The findings from this study indicate that symptom distress lowers quality of life by two routes, indirectly through appraisal and by directly affecting quality of life. Although symptom distress is often considered an important variable in the newly-diagnosed phase of breast cancer, it is also important during the survivor phase (Ferrell et al, 1997; Ganz et al., 1996; Ganz et al., 1998), and bears careful assessment because of its negative effect on quality of life.

Appraisal did not mediate the relationship between optimism and quality of life. Optimism had a significant bivariate relationship with both appraisal and quality of life (see Table 2) but, in the multivariate regression analyses, it did not make a significant independent contribution to either ap- praisal or quality of life, probably because optimism was moderately correlated with many of the other independent variables. Given the important role that optimism has played in predicting adjustment to illness in other studies, particularly in studies of breast cancer patients (Carver et al., 1993), further research needs to be conducted on the role of optimism in predicting the quality of life of African American women with breast cancer.

Family functioning had a significant direct effect on quality of life that was not mediated by appraisal. Women who reported more satisfaction with their family's ability to help and support them reported a higher quality of life. Other investigators have also reported that a supportive family environment helps women to adjust to breast cancer (Hough et al., 1991). This finding underscores the importance of including family members in programs of care, so that they can learn more about the illness and maintain a supportive role with the ill family member.

Cancer recurrence also had a significant direct effect on quality of life that was not mediated by appraisal. Women whose cancer recurred reported a lower quality of life. There is a growing awareness that cancer recurrence is a difficult period for women with breast cancer (Northouse, Dorris, \& Charron-Moore, 1995), and that it is a period of time when women may need more assistance from health professionals in order to maintain their quality of life.

In summary, the model testing aspect of this study suggests that our preliminary model may need to be revised. Appraisal remains a key variable in the model but it appears to partially mediate rather than fully mediate the effects of the antecedents on quality of life. Further research is needed to refine the model and to examine if there are other factors that may affect either appraisal or quality of life.

In spite of the generally supportive findings that resulted from this study, there are some limitations that need to be taken into consideration. First, the analysis and discussion of findings implies some causality or linear relationships among the variables tested in the model which need to be viewed with caution, given the cross-sectional, correlational design of the study. Second, there may have been some measurement overlap among the concepts thought to be predictors of quality of life (e.g., Family APGAR) and one or more dimensions of quality of life (e.g., social-family dimension). However, when we examined the correlations between the scores on the Family APGAR and the quality of life measure, excluding the 
social-family dimension, we still found a significant relationship $(r=.30, p<.01)$ even though the size of the correlation was somewhat smaller than when the social-family dimension was included in the quality of life scale $(r=.40, p<.01)$. Thus, while there may be some measurement overlap, family functioning (Family APGAR) is related to quality of life whether or not the socialfamily dimension of quality of life is included in the analysis. Third, the results of this study were obtained from a convenience sample, rather than from a population-based sample of African American women with breast cancer, who were on the average well-educated. Hence, the results of this study may not be generalizable to a more socioeconomically diverse group of African American women with breast cancer. Fourth, only quantitative assessments were made of women's experiences and quality of life. The addition of a qualitative assessment may have added to the richness and depth in understanding factors that affect the quality of life of African American women with breast cancer. In addition, qualitative studies often tap positive aspects of breast cancer survivorship (Carter, 1993; Ferrans, 1994; Pelusi, 1997) or the meaning the illness may have for women (Mathews, Lannin, \& Mitchell, 1994) that are seldom assessed in quantitative studies.

In spite of the limitations, the findings suggest some potential implications for clinical practice. First, although the research literature and public media often focus on the cancer fatalism or lower survival rates of African American women with breast cancer, the findings of this study suggest that there is a need to inform the public about the other side of the story - that a number of African American women are able to manage the difficult aspects of breast cancer and enjoy a relatively high quality of life following diagnosis. In this same regard, it may be helpful for public service announcements to portray African American women, not just Caucasian women, as coping effectively following a breast cancer diagnosis. Hearing positive reports about the generally high quality of life of African American women with breast cancer and seeing positive images of them in the media may help to lessen cancer fatalism among African American women and help them to feel more confident about their ability to manage the illness and its treatments.

Second, the findings of this study underscore the importance of assessing how women appraise their illness and helping those women with a more stressful view of the illness to find ways to lessen it. For example, health professionals who are designing intervention studies for African American women with breast cancer may find it helpful to build in strategies that assist women with managing non-illness-related concerns (e.g., concerns about children, spirituality) as well as with illnessrelated concerns (e.g., symptom distress). Although most intervention protocols are highly structured to address only problems related to the illness, our findings suggest that it may be useful to address some non-illness-related concerns because these concerns may lead to a more negative appraisal of the illness and indirectly lower women's quality of life.

Third, health professionals need to assess symptom distress among breast cancer survivors and assist them with ways to manage it. Even though the women in this study did not have a great deal of symptom distress across a number of different symptom categories, they did have considerable distress in a few specific areas related to energy loss, sensory disturbances, sleep problems, and pain. There are reports that breast cancer survivors often feel frustrated as they try to seek help for these ongoing physical concerns. Some women have reported that health professionals often minimize their concerns and send them the message that instead of worrying about symptoms, they should be grateful they survived the disease (Ferrell et al., 1997). Assessment of the presence and severity of symptom distress, as well as the acknowledgment of the difficulty that these symptoms can create for breast cancer survivors, need to be a routine part of care (Ferrans, 1994).

In summary, the quality of life of African American women with breast cancer was found to be relatively high. Certain person, resource, and illness-related factors affected to varying degrees how the women appraised their illness and the level of quality of life that they reported. Future research is needed to test interventions that will assist African American women to decrease or resolve their current concerns, maintain their family support, and reduce symptom distress, so that these women can maintain a high quality in their lives in spite of the breast cancer.

\section{REFERENCES}

Aaronson, N.K. (1993). Assessment of quality of life and benefits from adjuvant therapies in breast cancer. Recent Results in Cancer Research, 127, 201-210.

Andrykowski, M.A., Curran, S.L., Studts, J.L., Cunningham, L., Carpenter, J.S., McGrath, P.C., Sloan, D.A., \& Kenady, D.E. (1996). Psychosocial adjustment and quality of life in women with breast cancer and benign breast problems: A controlled comparison. Journal of Clinical Epidemiology, 49, 827-834. 
Baron, R.M., \& Kenny, D.A. (1986). The moderatormediator variable distinction in social psychological research: Conceptual, strategic, and statistical considerations. Journal of Personality and Social Psychology, 51, 1173-1182.

Boring, C.C., Squires, T.S., \& Heath, C.W. (1992). Cancer statistics for African Americans. CA: Cancer Journal for Clinicians, 42, 7-18.

Brady, M.J., Cella, D.F., Mo, F., Bonomi, A.E., Tulsky, D.S., Lloyd, S.R., Deasy, S., Cobleigh, M., \& Shiomoto, G. (1997). Reliability and validity of the Functional Assessment of Cancer Therapy-Breast quality of life instrument. Journal of Clinical Oncology, 15, 974-986.

Burack, R.C., Gimotty, P.A., Stengle, W., Eckert, D., Warbasse, L., \& Moncrease, A. (1989). Detroit's avoidable mortality project: Breast cancer control for inner city women. Public Health Reports, 104, 527535.

Carey, P.J., Oberst, M.T., McCubbin, M.A., \& Hughes, S.H. (1991). Appraisal and caregiving burden in family members caring for patients receiving chemotherapy. Oncology Nursing Forum, 18, 1341-1348.

Carter, B.J. (1993). Long-term survivors of breast cancer. Cancer Nursing, 16, 354-361.

Carver, C., Pozo, C., Harris, S.D., Noriega, V., Scheier, M.F., Robinson, D.S., Ketcham, A.S. , Moffat, F.L., \& Clark, K.C. (1993). How coping mediates the effect of optimism on distress: A study of women with early stage breast cancer. Journal of Personality and Social Psychology, 65, 375-390.

Carver, C.S., Pozo-Kaderman, C., Harris, S.D., Noriega, V., Scheier, M.F., Robinson, D.S., Ketcham, A.S., Moffat, F.L., \& Clark, K.C. (1994). Optimism versus pessimism predicts the quality of women's adjustment to early stage breast cancer. Cancer, 73, 1213-1220.

Cella, D.F., Tulsky, D.S., Gray, G., Sarafian, B., Linn, E., Bonomi, A., Silberman, M., Yellen, S., Winicour, P., Brannon, J., Eckberg, K., Lloyd, S., Purl, S., Blendowski, C., Goodman, M., Barnicle, M., Stewart, I., McHale, M., Bonomi, P., Kaplan, D., Taylor, S., Thomas, C.R., \& Harris, J. (1993). The Functional Assessment of Cancer Therapy Scale: Development and validation of the general measure. Journal of Clinical Oncology, 11, 570-579.

Cohen, J. (1988). Statistical analysis for the behavioral sciences (2nd ed.). Hillsdale, NJ: Lawrence Erlbaum Associates.

Dayal, H.H., Power, R.N., \& Chiu, C. (1982). Race and socio-economic status in survival from breast cancer. Journal of Chronic Disease, 35, 675-683.

Dorval, M., Maunsell, E., Deschenes, L., Brisson, J., \& Masse, B. (1998). Long-term quality of life after breast cancer: Comparison of 8-year survivors with population controls. Journal of Clinical Oncology, 16, 487-494.

Ferrans, C.E. (1994). Quality of life through the eyes of survivors of breast cancer. Oncology Nursing Forum, 21, 1645-1651.

Ferrell, B., Grant, M., Funk, B., Garcia, N., Otis-Green, S., \& Schafferner, M.L. (1996). Quality of life in breast cancer. Cancer Practice, 4, 331-340.
Ferrell, B., Grant, M., Funk, B., Otis-Green, S., \& Garcia, N. (1997). Quality of life in breast cancer Part I: Physical and social well-being, Cancer Nursing, 20, 398-408.

Ferrell, B., Grant, M., Funk, B., Otis-Green, S., \& Garcia, N. (1998). Quality of life in breast cancer Part II: Psychological and spiritual well-being. Cancer Nursing, 21, 1-9.

Ferrell, B.R., Hassey Dow, K., \& Grant, M. (1995). Measurement of the quality of life of cancer survivors. Quality of Life Research, 4, 523-531.

Ferraro, K.F. (1993). Are Black older adults health-pessimistic? Journal of Health and Social Behavior, 34, 201-214.

Flesch, R. (1974). The art of readable writing. New York: Harper \& Row.

Freeman, H.P., \& Wasfie, T.J. (1989). Cancer of the breast in poor black women. Cancer, 63, 2562-2569.

Ganz, P.A., Coscarelli, A., Fred, C., Kahn, B., Polinsky, M.L., \& Petersen, L. (1996). Breast cancer survivors: Psychosocial concerns and quality of life. Breast Cancer Research and Treatment, 38, 183-199.

Ganz, P.A., Rowland, J.H., Desmond, K., Meyerowitz, B., \& Wyatt, G.E. (1998). Life after breast cancer: Understanding women's health-related quality of life and sexual functioning. Journal of Clinical Oncology, 16, 501-514.

Grassi, L., \& Rosti, G. (1996). Psychosocial morbidity and adjustment to illness among long-term cancer survivors. Psychosomatics, 37, 523-532.

Hough, E.E., Lewis, F.M., \& Woods, N.F. (1991). Family response to mother's chronic illness: Case studies of well- and poorly adjusted families. Western Journal of Nursing Research, 13, 568-596.

Kang, S.H., \& Bloom, J. (1993). Social support and cancer screening among older Black Americans. Journal of the National Cancer Institute, 85, 737742.

Lauver, D. (1992). Psychosocial variables, race and intention to seek care for breast cancer symptoms. Nursing Research, 41, 236-241.

Lazarus, R., \& Folkman, S. (1984). Stress, appraisal and coping. New York: Springer.

Lewis, F.M., Hammond, M.A., \& Woods, N.F. (1993). The family's functioning with newly diagnosed breast cancer in the mother: The development of an explanatory model. Journal of Behavioral Medicine, 16, 351-370.

Lewis, F.M., Zahlis, E.H., Shands, M.E., Sinsheimer, J.A., \& Hammond, M.A. (1996). The functioning of single women with breast cancer and their schoolaged children. Cancer Practice, 4, 15-24.

Longman, A.J., Braden, C.J., \& Mishel, M.H. (1996). Side effects burden in women with breast cancer. Cancer Practice, 4, 274-280.

Mathews, H.F., Lannin, D.R., \& Mitchell, J.P. (1994). Coming to terms with advanced breast cancer: Black women's narratives from Eastern North Carolina, Social Science and Medicine, 38, 789-800.

Maunsell, E., Brisson, J., \& DeSchenes, L. (1992). Psychological distress after initial treatment of breast cancer. Cancer, 70, 120-125. 
Mood, D., \& Bickes, J. (1989). Strategies to enhance self-care in radiation therapy. Oncology Nursing Forum (Supplement), 16, 143.

Mood, D., Northouse, L.L., \& Oberst, M. (1995). Psychosocial interventions in radiation therapy. (Grant \#R01CA59013), National Cancer Institute.

Munkres, A., Oberst, M.T., \& Hughes, S.H. (1992). Appraisal of illness, symptom distress, self-care burden, and mood states in patients receiving chemotherapy for initial and recurrent cancer. Oncology Nursing Forum, 19, 1201-1209.

Northouse, L.L., Dorris, G., \& Charron-Moore, C. (1995). Factors affecting couples' adjustment to recurrent breast cancer. Social Science and Medicine, 41, 69-76.

Northouse, L.L., Jeffs, M., Cracchiolo-Caraway, A., Lampman, L., \& Dorris, G. (1995). Emotional distress reported by women and husbands prior to a breast biopsy. Nursing Research, 44, 196-201.

Northouse, L.L., \& Swain, M.A. (1987). Adjustment of patients and husbands to the initial impact of breast cancer. Nursing Research, 36, 221-225.

Northouse, L.L., Templin, T., Mood, D., \& Oberst, M.T. (1998). Couples' adjustment to breast cancer and benign breast disease: A longitudinal analysis. PsychoOncology, 7, 37-48.

Oberst, M.T. (1991). Appraisal of illness scale: Manual for use. Detroit: Wayne State University.

Oberst, M.T., Hughes, S.H., Chang, A., \& McCubbin, M. (1991). Self-care burden, stress appraisal, and mood among persons receiving radiotherapy. Cancer Nursing, 14, 71-78.

O’Hare, P.A., Malone, D., Lusk, E., \& McCorkle, R. (1993). Unmet needs of black patients with cancer post hospitalization: A descriptive study. Oncology Nursing Forum, 20, 659-664.

Pelusi, J. (1997). The lived experience of surviving breast cancer. Oncology Nursing Forum, 24, 13431353.

Penman, D.T., Bloom, J.R., Fotopoulous, S., Cook, M.R., Holland, J.C., Gates, C., Flamer, D., Murawski, B., Ross, R., Brandt, U., Muenz, L.R., \& Pee, M (1986). The impact of mastectomy on self-concept and social function: A combined cross-sectional and longitudinal study with comparison groups. Women \& Health, 11, 101-130.

Phillips, J.M., Cohen, M.Z., \& Moses, G. (1999). Breast cancer screening and African American Women: Fear, fatalism, and silence. Oncology Nursing Forum, 26, 561-571.

Powe, B.D. (1995). Cancer fatalism among elderly Caucasians and African Americans. Oncology Nursing Forum, 22, 1355-1359.

Powe, B.D., \& Weinrich, S. (1999). An intervention to decrease cancer fatalism among rural elders. Oncology Nursing Forum, 26, 583-588.
Powell, D.R. (1994). Social and psychological aspects of breast cancer in African American women. Annals of the New York Academy of Sciences, 736, 131139.

Price, J.H., Desmond, S.M., Slenker, S., Smith, D., \& Stewart, P.W. (1992). Urban Black women's perceptions of breast cancer and mammography. Journal of Community Health, 17, 191-203.

Reynolds, P., Boyd, P.T., Blacklow, R.S., Jackson, J.S., Greenberg, R.S., Austin, D.F., Chen, V., Edwards, B.K., and the National Cancer Institute Black/White Cancer Survival Study Group. (1994). The relationship between social ties and survival among Black and White breast cancer patients. Cancer Epidemiology, Biomarkers, \& Prevention, 3, 253-259.

Scheier, M.F., \& Carver, C.S. (1985). Optimism, coping, and health: Assessment, and implications of generalized outcome expectancies. Health Psychology, 4, 219-247.

Scott, D.W., Oberst, M.T., \& Dropkin, J.M. (1980). A stress-coping model. ANS: Advances in Nursing Science, 3(1), 9-23.

Smilkstein, G. (1978). The Family APGAR: A proposal for a family function test and its use by physicians. Journal of Family Practice, 6, 1231-1239.

Smilkstein, G., Ashworth, C., \& Montano, D. (1982). Validity and reliability of the Family APGAR as a test of family function. Journal of Family Practice, 15, 303-311.

Taylor, R.J., \& Chatters, L.M. (1986). Patterns of informal support to elderly black adults: Family, friends, and church members. Social Work, 31, 432438.

Vinokur, A.D., Threatt, B.A., Caplan, R.D., \& Zimmerman, B.L. (1989). Physical and psychological functioning and adjustment to breast cancer: Long-term follow-up of a screening population. Cancer, 63, 394-405.

Vinokur, A.D., Threatt, B.A., Vinokur-Kaplan, D., \& Satariano, W. (1990). The process of recovery from breast cancer for younger and older patients. Cancer, 65, 1242-1254.

Weisman, A.D., \& Worden, W.J. (1977). The existential plight in cancer: Significance of the first 100 days. International Journal of Psychiatry in Medicine, 7, 115.

Woods, N., \& Earp, J.L. (1978). Women with cured breast cancer. Nursing Research, 27, 279-285.

Worden, W.J. (1983). Psychosocial screening of cancer patients. Journal of Psychosocial Oncology, 1, $1-10$.

Wyatt, G., \& Friedman, L.L. (1996). Long-term female cancer survivors: Quality of life issues and clinical implications. Cancer Nursing, 19, 1-7. 